\title{
Majority Rule, Compromise and the Democratic Legitimacy of Referendums ${ }^{1}$
}

Abstract: Cheneval and el-Wakil (2018c) defend referendums as a mechanism that allows a popular majority to express itself in situations where the standard channels of representative democracy fail to include the concerns of certain citizens and end up reflecting the views of a minority. By contrast, this comment argues that the likelihood of exclusion and settlement on a minority preference is much greater when policy choices are made by referendum. The reason lies in the plurality of policy options on many issues, and the fact that the most favoured policy may be a shared second or third best. The tendency for most forms of representative democracy to encourage politicians to build majorities through compromises among different coalitions of minorities is more likely to settle on the majority preference of diverse actors holding a plurality views than a referendum based on a binary choice.

Key words: Majority Rule, Compromise, Pluralism, Representation, Referendums

When we assess the legitimacy of a political system we need to look not only at each institution taken on its own but also at the ways they interact with each other. For example, an important aspect of any appraisal of the operation of a country's judiciary will be its relationship to the executive and legislature. Attention to the institutional mix need not necessarily be because we believe such a system should endeavour to realise a number of different values. It can also be because realising the core value we seek from a political system requires a complex set of institutions. For example, debates about the respective roles of constitutional courts and democratic legislatures have been framed by some as balancing two distinct values, individual rights and popular sovereignty, and by others as being about the balance between the two institutions necessary to realise a single value, such as freedom as non domination or equality of concern and respect. Nevertheless, the terms of the evaluation - the values or value we believe a political system should support and promote will influence our assessment of the optimal institutional mix.

\footnotetext{
${ }^{1}$ I am grateful to Albert Weale and the journal's referees for helpful comments on an earlier draft.
} 
A great strength of Cheneval and el-Wakil's (2018c) defence of referendums derives from their taking this interactive and holistic approach. As Cheneval and el-Wakil (2018c) note, many of the standard criticisms of referendums gain leverage from portraying them as direct democratic alternatives to representative democracy. These criticisms potentially have less force when referendums are seen as one of a number of democratic mechanisms that might be required to support the democratic quality of the political system as a whole. Moreover, Cheneval and el-Wakil (2018c) regard these democratic mechanisms as together serving a single normative purpose of ensuring that the processes of democratic decision-making can be regarded as neutral and fair from the standpoint of "the degree and quality of inclusion of all citizens' in collective decision-making. On this account, the legitimacy of the democratic process is outcome independent, although they concede certain outcomes may be "completely undesirable" and "need to be excluded beforehand by restricting the domain of majoritarian government," presumably by some form of constitutional constraints. The role Cheneval and el-Wakil (2018c) assign to referendums is a supplementary one, therefore: namely, that of adding an additional channel to the standard electoral and legislative processes associated with representative democracy with the aim of rectifying certain alleged failures to adequately include the concerns of some citizens in decision-making. I agree with this approach, so hopefully our arguments can avoid talking past each other. However, Cheneval and el-Wakil (2018c) fail to specify either the values by which we are to adjudge a process as neutral and fair, or to define those values that render a decision “completely undesirable." For the purposes of this comment, I shall assume a single value underlies both issues - that of securing non-domination. As Philip Pettit (2000; 2012, 146-49, 152-53) has argued, that value supports a content independent account of democratic legitimacy that gives a key role to supplementary contestatory mechanisms of the kind they associate with a referendum - that of providing "a collective right to refute," that allows "a 
governmental or parliamentary legislative decision" to be challenged. As such, it supplies a suitable standard for evaluating their argument.

Cheneval and el-Wakil (2018c) argue that referenda "are especially valuable in one chamber parliamentary systems and in consensus democracy characterised by coalition governments, in which decisions punctually or cumulatively might move away from what a majority finds acceptable." The argument here appears to be that a government of representatives of different minorities might on occasion subvert the preferences of a majority of people. They allege this distortion can occur for certain unspecified "self-serving" motives among the representatives. Later in the text they elaborate further and suggest, as they put it in the Conclusion, that it is "a device for empowering unelected minorities to challenge decisions of elected representatives" by appealing to a popular majority directly themselves. This additional specification could simply mean that for organisational reasons it will always be a minority that will trigger a referendum. But it could possibly suggest that this mechanism could allow a direct appeal by a minority to the majority to rethink measures done in their name that they consider dominating.

In what follows I shall contest both possibilities. I shall argue such referendums risk being a mechanism whereby a majority dominates a minority, on the one side, and a minority dominates the majority, on the other. I do not deny that contestatory mechanisms, such as courts or second chambers, can be necessary supplements within any well-functioning political system, but referendums may not be the most legitimate or effective. Indeed, I shall argue that, from a holistic point of view, their drawback lies precisely in a failure to appreciate the interconnectedness of people's preferences in a fair and value neutral way. I shall start by defining non-domination, noting how it offers a content independent criterion 
for a democratic system that involves not only majority rule but also requires compromise and, in given circumstances, consensus. I then turn to the ways a referendum might be dominating in challenging such settlements.

\section{Non-Domination and Democracy: Majority Rule, Compromise and Consensus}

Non-domination can be defined as the absence of alien, non-deliberative control (Pettit 2012,

ch. 1). Deliberative control, whereby others seek to persuade you via reasons you can accept or not, respects one's equal status as an independent reasoner and so involves no domination. By contrast, an agent or agency exercises non-deliberative control over your choices when they influence them either directly, be it through coercive interference or, more subtly, by manipulation or deception, or indirectly, without actual interference, through your simply fearing or anticipating their capacity to interfere and inhibiting your actions as a result of invigilation or monitoring, in ways that may lead to self-censorship or self-ingratiation. Both the interfering and the inhibiting kind of domination result from the actual or potential mastery of an agent or agents by another agent or agents. In both cases, domination derives from a situation in which one is no longer an equal and independent chooser.

Non-domination does not rule out the possibility that individuals might converge on a rational consensus. It merely insists that they must do so autonomously. However, in most cases they will reasonably disagree, either because of the limitations of practical reasoning John Rawls (1993, 55-56) termed "the burdens of judgment” or, more contentiously, due to an ineliminable pluralism of values and interests that render conflicting perspectives inevitable. Either way, in the case of such disagreements one will require a decisive yet fair way of resolving the matter that even those on the losing side regard as non-dominating and hence legitimate. To be so regarded, the collective decision-making process will need to be 
both suitably inclusive and content independent. In particular, it must be conducive to all the parties involved treating each others' views and interests with equal concern and respect in ways that lead them to hear and engage with the other side, with no person or persons being able to unduly influence others to adopt a position they favour, and it must not be biased as a process towards any given set of views or interests.

A democratic system will be non-dominating, therefore, to the extent it treats all citizens equally as autonomous sources of reasons, allows for free and fair deliberation, and involves collective decision-making that is impartial with respect to both the views people hold and who holds them. Hence a legitimate democratic process must handle all persons' views and interests equally, anonymously and neutrally - that is it is not inherently biased to any given view or group of people, while being positively responsive to how many people hold a given view and capable of producing a conclusive decision (Christiano 2008). A democratic decision procedure based on one person one vote and majority rule operates in just such a non-dominating manner (May 1952). However, it does so assuming that the voting concerns a single issue in which all those involved have an equal stake - that is, they will all be roughly speaking equally impacted by it - and that only two options are being voted on, none of which can be regarded as conducive per se to domination and hence as falling into the category of 'completely undesirable'.

Four problems arise here. First, most democratic decision-making involves a range of issues and has to give consideration to the knock-on effects of a decision on one issue for other issues. Second, and relatedly, when more than two options are in play there may be no clear majority preference. As I note below, there may be a majority cycle. Third, and also relatedly, citizens may have a roughly equal stake in the general package of decisions taken 
collectively but not in each and every one of them. There may even be some subset of decisions that only some groups of citizens have an equal stake in rather than all citizens. Finally, the category of the "completely undesirable" may also be a matter of reasonable disagreement. I shall argue that to the extent these problems exist, compromise among elected representatives may be democratically legitimate rather than self-serving in order to treat citizens in a non-dominating fashion (Bellamy 1999, ch. 5). By contrast, as the next section shall argue, a referendum contesting such a settlement by appealing to the majority will of the people may be arbitrary and potentially dominating.

With regard to the first problem, majority rule can appear to provide a decision on a single issue in a decisive and non-dominating way where there are only two options and a single issue at stake. It becomes more complicated beyond that simple case once people are deciding their preferences with regard to more than two options. Take the example in Table 1.

Table 1 Condorcet voting as compromise

\begin{tabular}{|l|l|}
\hline Parties (\% of the vote) & Policy or candidate preference rankings \\
\hline Party A (25\%) & a b c d \\
\hline Party B (30\%) & b a d c \\
\hline Party C (40\%) & c a d b \\
\hline Party D (5\%) & d b c a \\
\hline
\end{tabular}

In this example, the plurality winner would be "c," since it is the first preference of the most people, and in systems such as the US and the UK would count as the "majority" view. However, "a" emerges as the Condorcet winner, that is the majority preference among all the options, when its ranking is compared against each of the alternatives. Arguably, any decision other than "a" could be regarded as dominating: it would not show equal concern and respect to the other preferences. Yet, for a majority to converge on "a" requires compromise (Bellamy 1999, 132-33; Weale 1999, 135-7). For example, it involves Party C 
not holding out for "a" on the grounds it is the first preference of the largest single group of people, but rather accepting a as a mutually preferable "second best."

Achieving such a compromise may not be something electors could do for themselves, for while they know their own preferences it can be hard to appreciate how they fit with those of other citizens. By contrast, parties can have incentives to find such a compromise. In two party systems, parties typically manage to offer a binary choice through being themselves coalitions. They attempt to construct a package built around how they believe a majority of voters would rank order a series of issues. For, when party competition operates within a one dimensional, Left-Right, electoral space, parties tend to converge on the median voter's preferred ordering of a package of issues, whose preferences happen to match those of the Condorcet winner (Ordeshook 1986, 254-67).

However, matters are likely to be more difficult still. The second problem arises here. Imagine the scenario in Table 2. Here we will have no Condorcet winner and instead have a majority cycle, whereby a beats b beats $\mathrm{c}$ beats $\mathrm{d}$ beats a ... (Weale 1999, 138). This scenario can easily arise once the electoral space becomes multidimensional. For example, in Europe left-right has become cross-cut by the competing Green-Alternative-Libertarian vs. Traditional-Authoritarian-Nationalist, or GAL-TAN, cleavage (Hooghe and Marks 2009). Imagine the preference orderings are now the party preferences for the package of policies they would agree on to form a coalition with other parties (Weale 2018). Now we see any majority coalition could potentially be defeated by another majority coalition. So a coalition led by A around policy package a beats a coalition led by B around policy package b, and so forth.

Table 2 Majority voting cycle 


\begin{tabular}{|l|l|}
\hline Parties (\% of the vote) & Policy or candidate preference rankings \\
\hline Party A (40\%) & a b c d \\
\hline Party B (20\%) & b d a c \\
\hline Party C (20\%) & $\mathrm{c} \mathrm{d} \mathrm{a} \mathrm{b}$ \\
\hline Party D (20\%) & $\mathrm{d} \mathrm{b} \mathrm{c} \mathrm{a}$ \\
\hline
\end{tabular}

The up side is that such cycles afford protection for minorities. Because an electoral majority is built from minorities and prone to cycling coalitions, a ruling group will do well not to rely on a minimal winning coalition and to exclude other groups entirely. Consequently, either a currently excluded minority has a good chance of being part of a future winning coalition, or - for that very reason - is likely not to be excluded entirely by any winning coalition keen to retain its long-term power (McGann 2004: 56, 71). Again, compromise wins the day.

Majority rule and compromise become harder in circumstances where not all citizens have an equal stake in many collective decisions due to a heterogeneity of social and economic interests between different localities, and where the normative assessments and modes of public reasoning of different groups of citizens differ in ways that are both incommensurable and incompatible, on account of a heterogeneity of cultural assumptions among various communities (Bellamy 1999, 123-31). The third and fourth problems enter here. As political societies become segmented, with vertical cleavages replacing cross-cutting horizontal cleavages, preferences become more polarised, making trade-offs harder. All states of a certain size allow for some devolution downwards to local government to deal with issues where only those in a given locality have an equal stake - not only because of socioeconomic diversity but also for functional reasons (Brighouse and Fleurbaey 2010). This tendency becomes more pronounced in states that are culturally heterogeneous. Here, majoritarian decision-making risks creating persistent minorities of one or more segmented group of citizens. In such segmentally divided societies, not only does one get the devolution of considerable power downwards but also what remains to be decided at the national level 
occurs through the institutions typical of "consociational" and "consensus" democracies that are designed to protect the salient interests and preferences of minority groups, often by giving them a proportional say (Jones 1988).

Again, such systems are typified by compromise among elected representatives. But such compromise reflects not simply pragmatic trade-offs and splitting of the difference, as is likely in the more homogenous societies, but also more demanding integrative compromises, that try and combine diverse and often divergent perspectives (Bellamy 1999, 111-113). In finding a common policy on abortion, say, compromises are attempted that give expression to certain concerns of both pro-life and pro-choice camps. A pro-choice policy can allow medical staff with religious objections not to perform abortions, negotiate the cut off date for abortions, perhaps allowing a longer period in cases of rape or when the mother's life is at risk, and so on. Such integrative compromises reflect a democratic principle that minorities should not be bound by majority decisions they deem "completely undesirable."

\section{Uncompromising Referendums and the Tyranny of the Majority}

The last section suggested that compromise and majority rule often go together, with the former making possible and legitimising the latter (Bellamy 2012). Compromises arise either through some convergence on a mutual second-best, as in settling on the Condorcet winner on a given issue, or by trade-offs that allow groups with different preference rankings for different issues to concede in areas they care less about to achieve more in areas closer to their heart - although this can lead to cycling. Each of these compromises can be related to the content independent democratic ethos of avoiding dominating your fellow citizens in circumstances where disagreement is reasonable (Bellamy 1999, ch 4). If I recognise that all

citizens are entitled to be viewed as equally reliable reasoners about our collective interest to 
me, and that we all, myself included, are partial to our own perspectives, so that no person or group of persons can claim infallibility in assessing complex policy issues, then - assuming all voters have an equal stake in how the community is run - even if I disagree with my fellow citizens, I will have a moral motive for seeking to include their views not only in the process of decision making, showing them equal respect, but also in the collective decision itself, showing equal concern (Weinstock 2013). Add to that uncertainty as to what the most preferred view of a putative majority is - or even what the majority is - then, it becomes important to try and integrate minority views, not for pragmatic or self-interested reasons say, so minority representatives can gain an unearned place at the top table - but for reasons of sustaining a democratic community based on the non-dominating virtues of showing each other equal concern and respect (Bellamy 2012). That moral requirement becomes even more vital in segmented societies, where minority oppression or exclusion becomes likely. Here we may have reason to at least grant minorities a proportional voice in the community, so they are not consistently outvoted on collective matters (Jones 1988), possibly by allowing a degree of self-government to different minority communities, or - more demandingly - to find ways whereby their concerns can be integrated into common policies, especially in areas where there is disagreement as to what is "completely undesirable."

If true, the above argument has damaging consequences for the specific contestatory role Cheneval and el-Wakil (2018c) attribute to referendums. As we saw, they regard it as allowing an organised minority of the electorate to contest a compromise among elected representatives of minorities by putting it to the popular vote with the aim of revealing where the true majority opinion lies. Take the example of Table 1. Supporters of "c" might appeal against a decision on "a," on the grounds it was initially supported by a minority of $25 \%$. Suppose they set the agenda so that the referendum was about repealing "a" and unpicking 
the compromise so "a" gets knocked out of consideration. Ironically, the result might be that the parties agree at a later stage on "b." Or suppose the situation is that of Table 2. Here no stable majority exists for any option. Again, which option emerged as the majority choice would depend on which pair was chosen for comparison, which would be largely arbitrary. The problem is that political choices are seldom binary. Indeed, for that very reason, parties tend to present voters with weighted packages of preferences and to negotiate among each other when forming coalitions on that basis. Extracting a single issue from the compromise could mean that its knock on effects for other issues failed to get appropriate weighting through not being part of the vote. Finally, matters become even more serious in the third example we considered. In this case, the attempt by one of the segmented groups to appeal to a majority of the population as a whole cannot avoid risking the domination of a minority.

I cannot see how Cheneval and el-Wakil's (2018c) advocacy of a signature threshold for triggering a bottom up referendum obviates these problems. True, with regard to the third example some have argued that referendums help overcome segmental cleavages: that regular national referendums have had a centripetal effect in creating a national demos in Switzerland, for example, while their absence in Belgium has reinforced the centrifugal trend towards the two linguistic communities becoming separate demoi (Lacey 2017). I disagree: the social conditions in the two cases are different. What legitimises referendums in Switzerland is the presence of cross-cutting cleavages of wealth and religion across the linguistic communities, whereas in Belgium the segmental character of the linguistic cleavage is reinforced through being a division between richer and poorer regions, with a historical background of the dominance of the once richer but now poorer French region (Bellamy forthcoming b). Hence, referendums in Belgium would risk undermining the national consensus achieved through strong consociational arrangements. Meanwhile, on 
other issues, such as immigration and the agreement regarding free movement and the EU, a danger still exists even in the Swiss case that the more complex policy preferences of people about such issues fail to be reflected in a binary choice.

Within pluralist societies, appeals to a popular majority are largely mythical (Weale 2018). They fail to give due recognition to the diversity and multiplicity of individual citizens' preferences. A content independent process that shows equal concern and respect to all views and interests so as to avoid any one dominating others cannot be a matter of simple majority rule in such circumstances. It requires a willingness to find integrative compromises that recognise each citizen's entitlement to be considered an equal member of the deliberative community. An appeal to a collective popular will that transcends that plurality of individual and group wills, as in a referendum, becomes almost by definition dominating. It allows agenda setting that curtails and frames the free choices of citizens, and prevents them giving equal consideration to all the options among which the community as a whole has to choose. In the process, it undermines compromises that result from doing just that.

\section{Conclusion}

Cheneval and el-Wakil (2018c) offer a defence of referendums as a valuable supplement to the compromises typical of representative democracy that they consider may be the products of a bargain among minorities or elites that goes against the view of the majority. By contrast, I have argued that in pluralist societies the danger is precisely the opposite: that a referendum, no matter how well designed, may subvert a compromise that reflects the majority and instead imposes a minority view. 
I should note that this argument applies particularly to 'policy' rather than 'constitutional' or 'constitutive' referendums (for this distinction see Tierney 2012: 14). In a 'constitutional' referendum, such as the UK vote on changing the electoral system or the Irish vote on abortion, the issue is likely to be both discreet and binary, although a risk might exist of the vote being on a "completely undesirable" proposal. A 'constitutive' referendum potentially has the same quality, being about whether a people wish to consider themselves a demos or not, as in the referendums on Scottish Independence and UK membership of the EU. Yet, for many voters in both these cases their vote was influenced also by an assessment of the policy implications of leaving or staying in the UK and the EU respectively. As a result, here too the binary choice may have masked the more complex plurality of preferences of the population and lead in practice to the least favoured choice of those concerned (Weale 2018).

\section{References}

Bellamy, Richard. 1999. Liberalism and Pluralism: Towards a Politics of Compromise. London: Routledge.

Bellamy, Richard. 2012. "Democracy, Compromise and the Representation Paradox: On Coalition Government and Political Integrity." Government and Opposition 47 (3): 441-465. Bellamy, Richard. Forthcoming 'Comment on Joseph Lacey, A Democratic Theory of Political Cohesion', Contemporary Political Thought

Brighouse, Harry and Marc Fleurbaey. 2010. "Democracy and Proportionality.” Journal of Political Philosophy 18 (2): 137-155.

Cheneval, F and el-Wakil, A. (2018c) 'The Institutional Design of Referendums: Bottom Up and Binding', Swiss Political Science Review, ???

Christiano, Thomas. 2008. The Constitution of Equality. Oxford: Oxford University Press. 
Hooghe, Liesbet and Garry Marks. 2009. “A Postfunctionalist Theory of European Integration: From Permissive Consensus to Constraining Dissensus." British Journal of Political Science 39 (1): 1-23.

Jones, Peter. 1988. “Intense Preferences, Strong Beliefs and Democratic DecisionMaking." Political Studies 36 (1): 7-29.

Lacey, J. (2017) Centripetal Democracy: Democratic Legitimacy and Political Identity in Belgium, Switzerland, and the European Union (Oxford: Oxford University Press). May, Kenneth 0. 1952. "A Set of Independent, Necessary and Sufficient Conditions for Simple Majority Decision." Econometrica 20 (4): 680-684.

McGann, Anthony J. 2004. "The Tyranny of the Supermajority: How Majority Rule Protects Minorities." Journal of Theoretical Politics 16 (1): 53-77.

Ordeshook, Peter C. 1986. Game Theory and Political Theory: An Introduction. Cambridge: Cambridge University Press.

Pettit, Philip. 2000. "Democracy, Electoral and Contestatory." Nomos 42: 105-44.

Pettit, Philip. 2012. On the People's Terms. Cambridge: Cambridge University Press.

Rawls, John. 1993. Political Liberalism. New York: Columbia University Press.

Tierney, S. (2012) Constitutional Referendums, Oxford: Oxford University Press

Weale, Albert. 1999. Democracy. Basingstoke: Palgrave.

Weale, Albert. 2018. The Will of the People: A Modern Myth. Cambridge: Polity.

Weinstock, Daniel. 2013. "On the Possibility of a Principled Compromise.” Critical Review of Social and Political Philosophy, 16 (4): 537-556.

\section{Biography}

Richard Bellamy is Professor of Political Science at University College, London (UCL) and Director of the Max Weber Programme at the European University Institute. His research interests include the history of European political thought post-1700, and 
contemporary analytical legal and political philosophy, focusing particularly on democracy, constitutionalism and citizenship. His A Republican Europe of Sovereign States: Cosmopolitan Statism, Republican intergovernmentalism and the Demoicratic Reconnection of the $E U$ is forthcoming from Cambridge University Press. 